\section{Skiing and snowboarding injury prevention}

\author{
Lynne J Warda, Natalie L Yanchar; Canadian Paediatric Society, Injury Prevention Committee
}

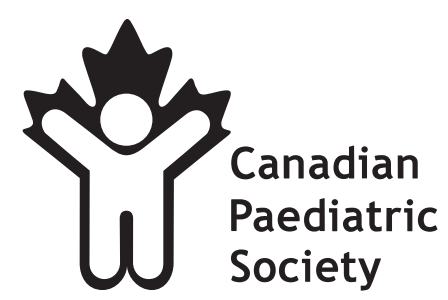

Full text at www.cps.ca Français en page 37

\begin{abstract}
Skiing and snowboarding are popular recreational and competitive sport activities for children and youth. Injuries associated with both activities are frequent and can be serious. There is new evidence documenting the benefit of wearing helmets while skiing and snowboarding, as well as data refuting suggestions that helmet use may increase the risk of neck injury. There is also evidence to support using wrist guards while snowboarding. There is poor uptake of effective preventive measures such as protective equipment use and related policy. Physicians should have the information required to counsel children, youth and families regarding safer snow sport participation, including helmet use, wearing wrist guards for snowboarding, training and supervision, the importance of proper equipment fitting and binding adjustment, sun safety and avoiding substance use while on the slopes.
\end{abstract}

Key Words: Helmet; Injury; Skiing; Snowboarding; Wrist guard

\title{
RECOMMENDATIONS
}

The Canadian Paediatric Society recommends the following:

- Physicians should provide office-based anticipatory guidance, counselling families to:

- Wear proper protective ski equipment, including a certified helmet, goggles, plus wrist guards for snowboarding;

- Receive formal instruction, followed by a graduated exposure to more challenging terrain and conditions under the supervision of an experienced participant;

- Become familiar with and adhere to the Alpine Responsibility Code;

- Ensure a safe environment, including adequate supervision, terrain/runs and equipment appropriate to the child or youth's age and ability;

- Ensure proper fit and adjustment of equipment, particularly bindings; and

- Understand the high risk of severe injury that comes with alcohol and/or drug use on the slopes.

- Governments should develop policy/legislation making helmet use mandatory by all ages while skiing and snowboarding, with concurrent messaging to educate the public and resort operators about the indisputable importance of helmets in saving lives and preventing head injuries.

- Ski areas/resorts/snowparks should develop and enforce safety policies that:

- Make helmet use mandatory;

- Improve helmet access at local ski facilities;

- Establish industry standards for ski shops and resorts on binding adjustment;

- Promote and enforce the Alpine Responsibility Code;

- Ensure safe design and prevention-oriented maintenance programs for ski facilities; and

- Promote safety awareness and education programs for participants, with consistent messaging and signage.

- Schools should develop policies mandating proper equipment use, formal instruction, and appropriate supervision for school-related trips, clubs and competitions.

- Research should be supported to address:

- Interventions to increase helmet and wrist guard use;

- Effective snow sport helmets and related design development and standards;

- Improved binding design (eg, multidirectional release), standards and optimal adjustment;

- The roles of preseason conditioning and training;

- The risk and profile of injuries at ski area terrain parks;

- The evaluation of existing interventions, such as promoting the Alpine Responsibility Code and 'Keep your Lid On,' to determine their effectiveness and improve uptake; and

- Ongoing surveillance of snow sports participation data for children, of emergency department, hospitalization, and mortality data for skiers and snowboarders, of protective equipment use, and of injuries due to ski/snowboard environments, such as falls in terrain parks and injuries related to ski lifts.

NOTE: For parent information, visit www.caringforkids.cps.ca. 
ACKNOWLEDGEMENTS: The authors thank Ms Gemma Briggs for her assistance with manuscript preparation. This position statement has been reviewed by the Acute Care, Adolescent Health, Community Paediatrics, and Healthy Active Living and Sports Medicine Committees of the Canadian Paediatric Society. This statement has been endorsed by the American Academy of Pediatrics.

\section{INJURY PREVENTION COMMITTEE}

Members: Claude Cyr MD; Brent E Hagel PhD; I Barry Pless MD; Jeffrey W Scott MD; Natalie L Yanchar MD (Chair); Mitchell Zelman MD (Board Representative)

Liaisons: Pamella Fuselli, Safe Kids Canada; Gail Salminen, Health Canada, Consumer Products Safety Bureau; Robin Skinner, Public Health Agency of Canada

Consultants: Matthew John Bowes MD; Amy Ornstein MD

Principal authors: Lynne J Warda MD (Past Chair, CPS Injury Prevention Committee); Natalie L Yanchar MD

The recommendations in this statement do not indicate an exclusive course of treatment or procedure to be followed. Variations, taking into account individual circumstances, may be appropriate. All Canadian Paediatric Society position statements and practice points are reviewed on a regular basis. Please consult the Position Statements section of the CPS website (www.cps.ca) for the full-text, current version. 